\title{
Development of an Olfactory Detector for the Evaluation of Fruit Aroma-A Proposed Approach
}

\author{
Orville Osmicote ${ }^{1}$ \\ Fruit Evaluation Laboratory, National Olfactory \& Sensory Experimental Station, Whiff Bay, \\ N.S. OD4 8PU, Canada \\ Charles F. Forney ${ }^{2}$, Jeffrey Richards ${ }^{3}$, and Chiam Liew ${ }^{3}$ \\ Research Centre, Agriculture and Agri-Food Canada, Kentville, N.S. B4N 1J5, Canada
}

\begin{abstract}
Aroma is an important quality characteristic in fresh fruits and vegetables. With the high demand for quality fruits and vegetables that do not stink, it is important to have reliable, qualitative, quantitative, and inexpensive methods to analyze aromas. The many unemployed students are a readily available, cheap source of olfactory sensors. This study describes the development and use of summer students as olfactory detectors. The objectives of the study were to 1) evaluate morphological characteristics of noses (olfactory detectors, OD) and their relationship to odor sensitivity and sample accommodation, 2) calibrate quantitative and qualitative responses of the OD, and 3) interface the OD to a strip chart recorder for efficient data collection.
\end{abstract}

\section{Materials and Methods}

Olfactory detector. Summer students were obtained at the local office of Employment and Immigration Canada. We chose students that exhibited a variety of morphological variation in their noses and that would work for minimum wage. We were able to find one student who volunteered to work just for the experience, in which case nose morphology was not used as a screening criterion. Morphological characteristics evaluated included length, width, curvature, and nostril aperture. Presence or absence of nose hair was noted. Nose types tested are shown in Fig. 1 (OD-1, OD-2, OD-3, and ODie-4).

Plant material. Fruit used for aroma evaluation were obtained from research plots or supermarket dumpsters, depending on availability. A variety of fruit were used to test the wide application of the analysis method, these included lowbush blueberries (Vaccinium augustifolium Aiton), strawberries (Fragaria $\times$ ananassa), raspberries (Rubus idaeus L.),

Received for publication 1 Apr. 1995. Accepted for publication 1 Apr. 1995. Contribution no. 2141 of the Kentville Research Centre. We thank Jane McDonald, Mike Jordan, and Willy Kalt for their helpful suggestions and encouragement throughout the study; Robert Prange and David Shaffelburg for their donation of summer students; and Andrew Schofield and CHOssekeag General GT Beauregard $\mathrm{CD}$ for their participation. The cost of publishing this paper was defrayed in part by the payment of page charges. Under postal regulations, this paper therefore must be hereby marked advertisement solely to indicate this fact.

${ }^{1}$ Sensory Scientist.

${ }^{2}$ Storage Physiologist, to whom reprint requests should be addressed.

${ }^{3}$ Summer Student.

HortScience, Vol. 30(2), April 1995 apples (Malus domestica Borkh), and watermelons [Citrullus lanatus (Thunb.) Matsum \& Nakai]. Fruit obtained from dumpsters was because it allowed us to evaluate fruit that the consumer normally would purchase. In addition, to fully test the OD, fruit from the dumpster was available in a variety of qualities and aromas. The change in aroma quality was a function of temperature and the number of days the fruit was in the dumpster (Fig. 2).

Aroma sampling. Sample introduction was achieved by placing the whole fruit $20 \mathrm{~mm}$ into the nostrils of the OD (Fig. 3). This procedure was quite effective with the blueberries, raspberries, and small strawberries, causing minimal damage to the fruit and allowing the same fruit to be analyzed several times and still be acceptable for consumer consumption. Following insertion of the fruit, the OD was instructed to inhale slowly so as preferred and was used whenever possible

not to dislodge the fruit. Rapid inhalations caused the fruit, particularly the lowbush blueberries, to be inhaled. In some cases, dislodged fruit could not be recovered, preventing their reanalysis and later consumption. Between samples, unsalted saltine crackers were inserted in the nostril and the nostril was rinsed with water to prevent sample carry over (Fig. $4 \mathrm{~A}$ and $\mathrm{B}$ ). When the detector was not in use, it was sealed to prevent olfactory fatigue and loss of sensitivity (Fig. 5). Note: lengthy storage periods may cause termination of $\mathrm{OD}$.

Data collection. Several methods were tested to collect the responses from the OD. The first method involved connecting wires from various locations on the OD to a strip chart recorder and measuring the millivolt output (Fig. 6). Several interface locations were tested, including each side of the right and left nostril, right and left temple, over the eyes, and for a whole body response, one wire

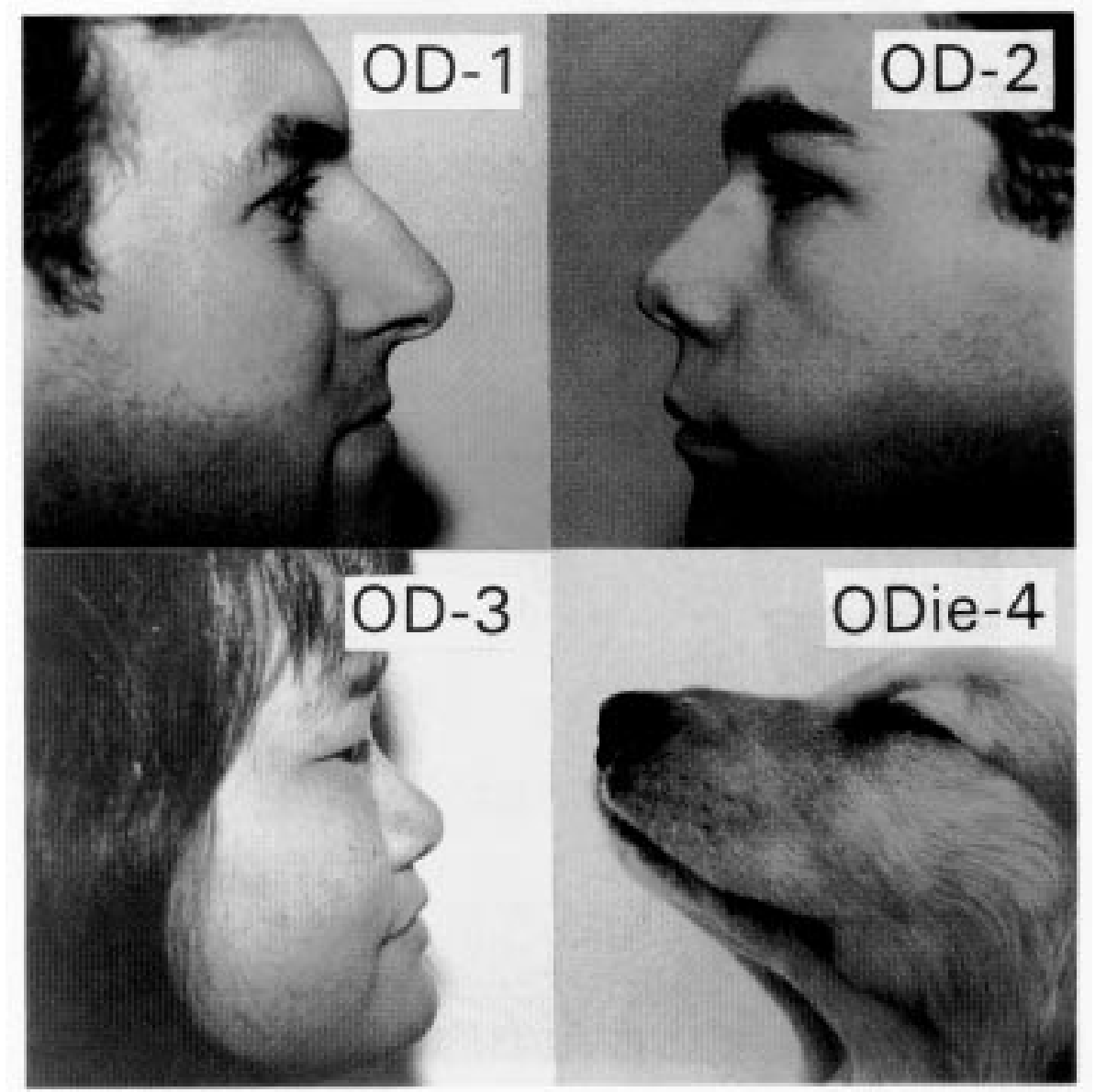

Fig. 1. Olfactory detectors (OD 1-4) used to evaluate fresh fruit. 


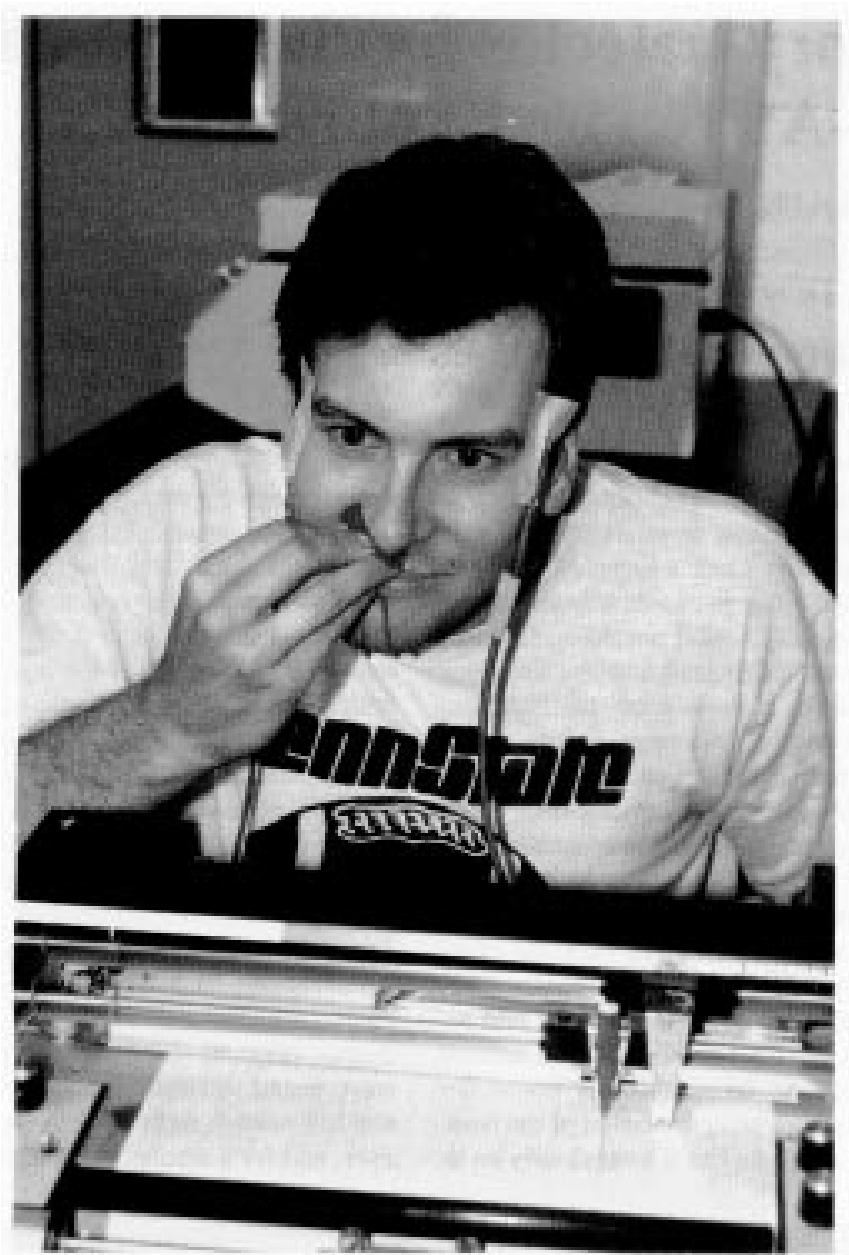

Fig. 2. Evaluation of a strawberry after 7 days of storage in dumpster.

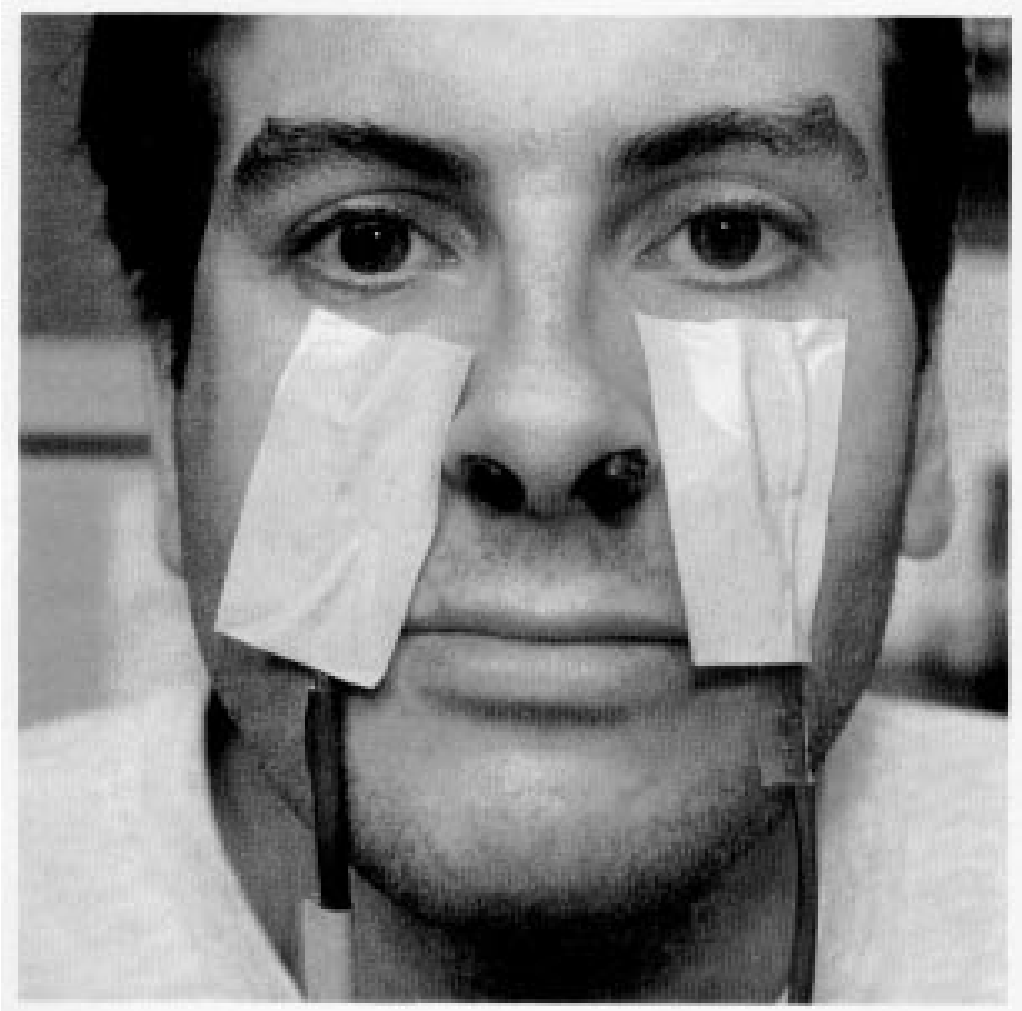

Fig. 3. Insertion of lowbush blueberries in OD-1. Note large aperture of OD-1 allowed insertion of two berries per nostril.
Table 1. Average peak response of strip chart recorder (in millivolts) connected to various locations on OD 1-4 during sniffing of fruit.

\begin{tabular}{lcccc}
\hline \hline & \multicolumn{4}{c}{ Wire location } \\
\cline { 2 - 5 } Fruit & \multicolumn{4}{c}{ Over } \\
Nostrils & Temples & $\begin{array}{c}\text { Whole } \\
\text { eyes }\end{array}$ \\
\hline Strawberry & $45 \pm 22^{z}$ & $23 \pm 6$ & $89 \pm 140$ & $3 \pm 11$ \\
Raspberry & $49 \pm 7$ & $77 \pm 54$ & $3 \pm 34$ & $27 \pm 9$ \\
Blueberry & $96 \pm 69$ & $7 \pm 32$ & $19 \pm 56$ & $62 \pm 38$ \\
Apple & $38 \pm 8$ & $83 \pm 65$ & $77 \pm 77$ & $37 \pm 1$ \\
Watermelon & NR $^{\mathrm{x}}$ & NR & NR & NR \\
\hline
\end{tabular}

${ }^{2}$ Values represent the mean of four detectors $\pm \mathrm{SE}$. yValues lost due to arm fatigue.

${ }^{\mathrm{x}} \mathrm{NR}=$ no response.

Table 2. Observed responses of ODs 1-4 to strawberries of varying aromatic quality.

\begin{tabular}{|c|c|c|c|c|}
\hline \multirow{2}{*}{$\begin{array}{l}\text { Days in } \\
\text { dumpster }\end{array}$} & \multicolumn{4}{|c|}{ Response } \\
\hline & OD-1 & OD-2 & OD-3 & ODie-4 \\
\hline 0 & Smiled & $\begin{array}{c}\text { Raised } \\
\text { eyebrows }\end{array}$ & $\begin{array}{c}\text { Closed } \\
\text { eyes }\end{array}$ & $\begin{array}{c}\text { Wagged } \\
\text { tail }\end{array}$ \\
\hline 2 & $\begin{array}{l}\text { Puffed } \\
\text { cheeks }\end{array}$ & Frowned & $\begin{array}{l}\text { Wrinkled } \\
\text { nose }\end{array}$ & Drooled \\
\hline 7 & $\begin{array}{c}\text { Slight } \\
\text { protrusion } \\
\text { of tongue }\end{array}$ & $\begin{array}{c}\mathrm{Gag} \\
\text { response }\end{array}$ & $\begin{array}{l}\text { Exhaled } \\
\text { rapidly }\end{array}$ & $\begin{array}{c}\text { Ate } \\
\text { sample }\end{array}$ \\
\hline
\end{tabular}

was connected to the left ear lobe and the other to the right small toe. Connecting the wires directly to the olfactory nerves was attempted, but the wires protruding from the nostrils damaged the fruit when it was inserted.

The second method involved recording the OD's facial expressions. Expressions recorded included mouth appearance, tongue response, respiratory activity, and facial expression.

\section{Results and Discussion}

The responses of the ODs to fruit aromas recorded on the strip chart recorder are summarized in Table 1, and a sample strip chart output is presented in Fig. 7. Wires located near nostrils were more sensitive to the putrid aromas. Whole-body response varied among OD-1-3. ODie-4 had to be removed from this part of the experiment as she was in heat at the time of sampling. Large variability was observed between ODs in the recorded millivolt responses. Also, background noise (as noted in Fig. 7) seemed to contribute more to peak aroma response than the actual fruit aroma. Unfortunately, this made the use of the strip chart interface unreliable.

Recording facial responses gave a better indication of aroma quality than millivolt response (Table 2). Negative responses increased with increasing time in the dumpster, with the exception of ODie-4 (Fig. 8). Correlations for ODie-4 could not be calculated due to loss of samples. Additional work must be conducted to calibrate facial response with aroma quality. However, with new advances in computer image analysis, we believe these responses could be quantifiable, thus resulting in a practical method for sensory evaluation of fruits. Other uses for this detector may include evaluating the aroma of vegetables, flowers, and other foods, as well as a diagnostic tool in identifying various spoilage organisms. 


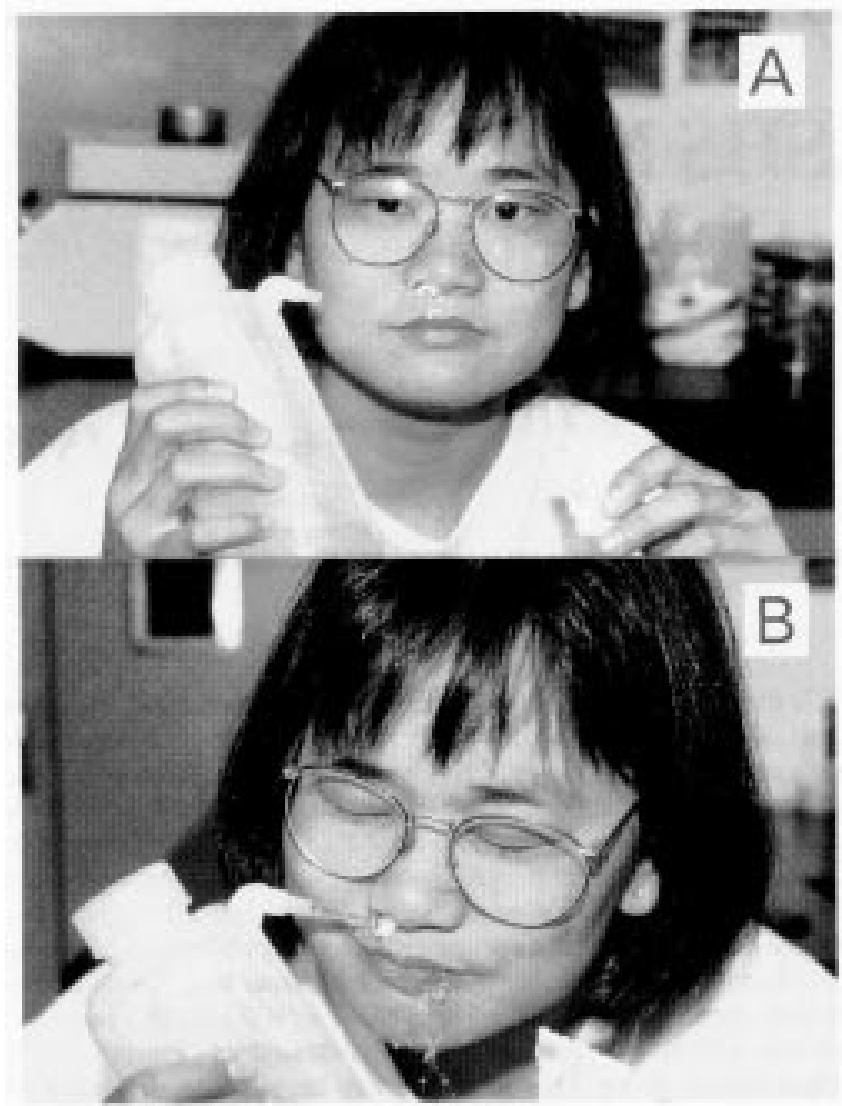

Fig. 4. Clearing OD-3 between fruit aroma analysis to eliminate carry over between samples. (A) Unsalted cracker was inserted into the nostril and (B) rinsed with $\mathrm{dH}_{2} \mathrm{O}$.

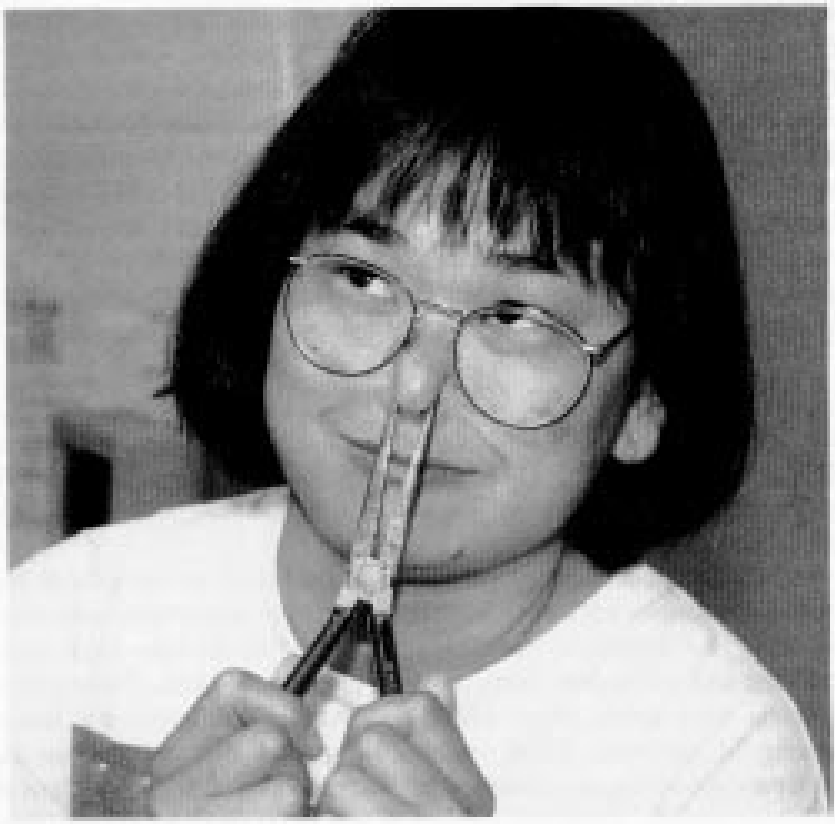

Fig. 5. Storage of OD between sample analysis using needlenose pliers, to prevent olfactory fatigue.

HorTSCIENCE, Vol. 30(2), APrIL 1995

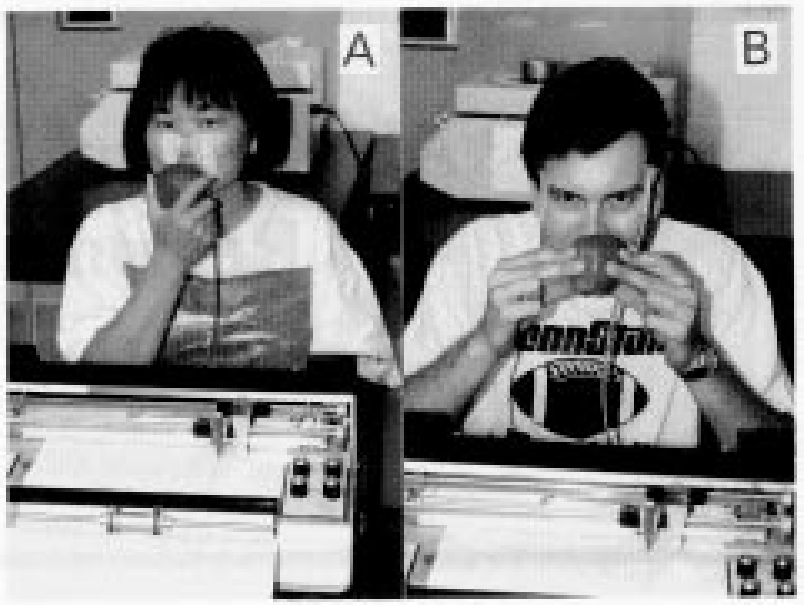

Fig. 6. Interfacing ODs with strip chart recorder through (A) nostril and (B) temple connections.

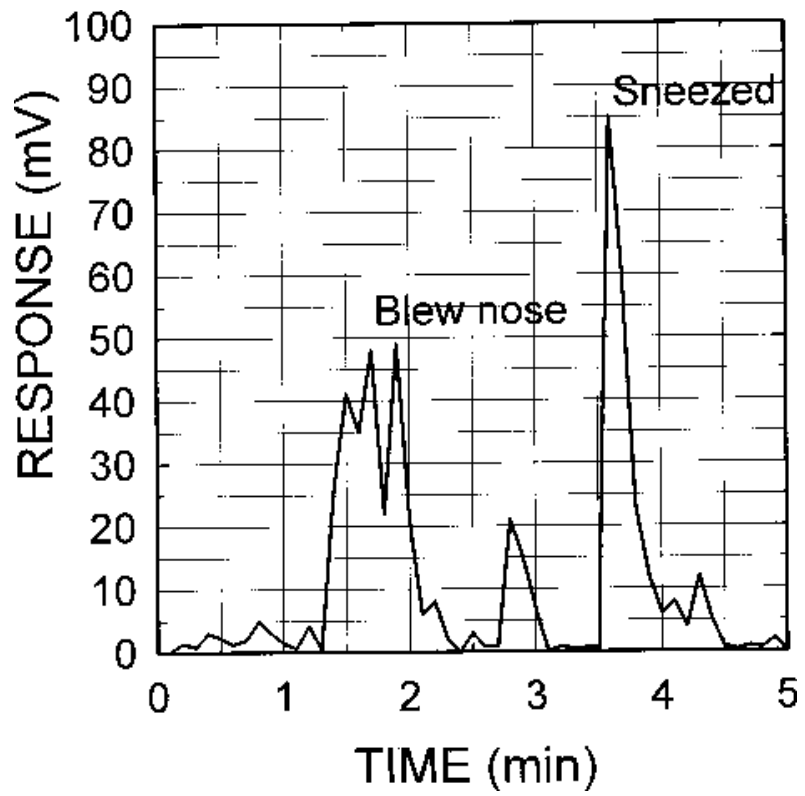

Fig. 7. Example of strip chart recorder output connected to temples of OD-3 during analysis of blueberry fruit.

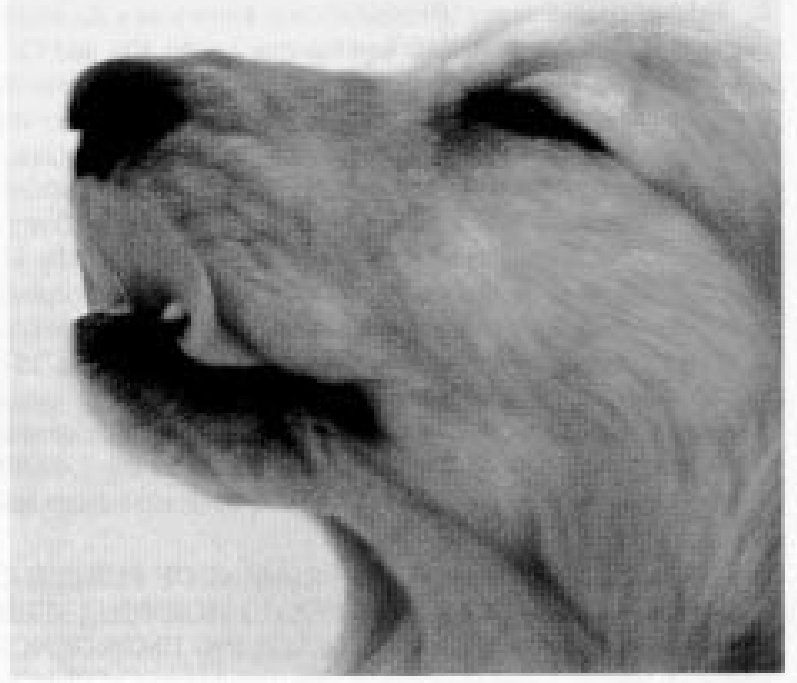

Fig. 8. ODie-4 following evaluation of strawberry stored in a dumpster for 7 days. 